Research Article

\title{
Evaluation of Collapsibility of Compacted Loess Based on Resistivity Index
}

\author{
Yongpeng Nie $\mathbb{C}^{1,},{ }^{1,2}$ Wankui Ni $\mathbb{D}^{1,2}$ Haiman Wang, ${ }^{1,2}$ Kangze Yuan, ${ }^{1,2}$ Wenxin Tuo, ${ }^{1,2}$ \\ and Xiangning $\mathrm{Li}^{1,2}$ \\ ${ }^{1}$ College of Geological Engineering and Geomatics, Chang'an University, Xi'an, Shaanxi 710054, China \\ ${ }^{2}$ Key Lab of Western Geological Resources and Geoengineering under Ministry of Education, Chang'an University, \\ Xian, Shaanxi 710054, China \\ Correspondence should be addressed to Wankui Ni; niwankui@chd.edu.cn
}

Received 25 March 2021; Revised 6 June 2021; Accepted 10 June 2021; Published 22 June 2021

Academic Editor: Miguel Angel Torres

Copyright $(92021$ Yongpeng Nie et al. This is an open access article distributed under the Creative Commons Attribution License, which permits unrestricted use, distribution, and reproduction in any medium, provided the original work is properly cited.

Recently, a lot of engineering constructions have been carried out in the Loess Plateau of China. However, the collapsibility of compacted loess as a filler poses a potential threat to the safety and stability of buildings. To address this threat, the scientific evaluation of the collapsibility of compacted loess has become a key to engineering construction. This study, therefore, tested the resistivity of compacted loess under varying conditions of water content, dry density, and its collapsibility coefficient under a pressure of $200 \mathrm{kPa}$. The correlation between collapsibility and electrical parameters was determined, and based on the resistivity, a new method to evaluate the collapsibility of the compacted loess is proposed. The results show that the resistivity of compacted loess decreases with an increase in water content and dry density and that the effect of water content is more significant. There is a critical water content value that causes the resistivity decay rate to slow down. The collapsibility coefficient also decreases with an increase in water content and dry density, and under the same dry density or same water content, the collapsibility coefficient and resistivity are positively correlated. According to the normalized resistivity value $\rho / \rho_{w}$, the relative collapsibility coefficient $\delta_{s}$ /0.015, and the water content $\omega$ obtained in the experiment, a collapsibility coefficient prediction model based on the resistivity of compacted loess was established. Using resistivity to evaluate the collapsibility of loess is nondestructive and provides a new method to accurately and quickly evaluate the collapsibility of compacted loess.

\section{Introduction}

Loess is a yellow silty sediment that is formed in the quaternary period and is gradually transported and accumulated over geological time $[1,2]$. Loess is widely distributed in China and is mainly concentrated in arid and semi-arid areas such as Shanxi, Shaanxi, southeastern Gansu, and western Henan, in the middle and upper reaches of the Yellow River. It covers a total area of about $640000 \mathrm{~km}^{2}$ and accounts for more than $6 \%$ of the national territory [3-6]. Collapsible loess accounts for about $60 \%$ of the total loess area in China. When collapsible loess is wetted by water under specific pressures or weights, its structure will be rapidly destroyed, which will reduce its strength and cause significant subsidence.
Currently, with the implementation and advancement of China's western development strategy, ever more infrastructure projects will start construction in the northwestern region of China where the loess is relatively collapsible [4]. During construction, materials are usually taken onsite, and the loess is compacted as foundation and roadbed filler [7]. The foundation settlement caused by the collapsibility of the loess $[8,9]$, slope instability $[10,11]$, and tunnel collapse [12] and other issues have, however, seriously affected the construction and operation of these infrastructure projects. The accurate and objective evaluation of the collapsibility of compacted loess, therefore, has important practical significance for the construction activities in loess areas.

Currently, two kinds of test methods are used to determine the collapsibility of loess. The first is the traditional 
indoor collapsibility test [13], which is simple, feasible, and economical. The second is the field immersion test [14]. The results of the field immersion test are more consistent with the actual collapsibility of loess at a field site, but the test period is long, the cost is high, and the site conditions are problematic. The laboratory test is therefore the most used method to evaluate the collapsibility of loess. However, the loess samples obtained at a certain location have specific location characteristics. If a large-scale collapsibility evaluation is to be performed, a large number of samples need to be taken at different locations, which will be time consuming and costly. Many scholars evaluated the collapsibility of loess by establishing the relationship between the physical and mechanical indexes and the collapsibility coefficient. Reznik [15] established a mathematical expression describing the relationship between the mechanical properties of collapsible loess and its porosity and water content. Gaaver [16] proposed a simple calculation formula to estimate the collapsibility of natural loess based on the initial water content. Zhang et al. [17] introduced the notion of the collapse sensitivity of loess and evaluated the loess collapsibility at a given site by using two indexes, namely, the time required for the degree of subsidence to reach $90 \%$ and the collapsibility coefficient under appropriate pressure. Wang et al. [18] proposed a new method to analyze and evaluate the collapsibility of loess based on the relationship between the compression characteristics of loess and the initial structure characteristics, as well as the relationship between the initial structure characteristics and physical comprehensive indexes. Most of the relations and empirical equations for estimating the collapsibility of loess are, however, based on various physical and mechanical properties that are difficult to determine. These include complex computational parameters, low determination coefficients, and many conditional constraints, which means that they are not widely used in practice. It is, therefore, necessary to find a new method to evaluate the collapsibility of compacting loess using simple and easy indoor indexes.

As a simple and practical geophysical detection technology, the resistivity method has become a widely used method in the field of geotechnical engineering. In recent years, many scholars have studied the relationship between the physical, mechanical, and engineering properties of soil and its resistivity index [19-21]. These research studies, however, focused on general sandy soils and viscous soils and not on collapsible loess. We, therefore, assess the usefulness of resistivity in the evaluation of the collapsibility of compacting loess.

In this study, a collapsibility test was carried out on the compacted loess with different dry densities and water contents, and a digital bridge was used to study the change in the resistivity of the compacted loess. Based on the correlation between the collapsibility of the compacted loess and the resistivity test results, a new prediction model of the collapsibility of the compacted loess is proposed, which can assist in the rapid evaluation of the collapsibility of the compacted loess.

\section{Materials and Methods}

2.1. Materials. The loess samples for this study were taken from Yan'an city, Shaanxi Province, China. Figure 1 is a schematic diagram of the main distribution locations and sampling locations of the Loess Plateau in Shaanxi Province. The sampling depth is $3 \mathrm{~m}$ below the surface, all of which are $Q_{3}$ loess. The specific process of sampling is as follows: after identifying the sampling site, the surface soil is removed and samples are manually obtained from the sampling depth to reduce disturbance. The samples are carefully cut into soil columns with a diameter of $10 \mathrm{~cm}$ and a height of $20 \mathrm{~cm}$. They are then immediately put into a sampling cylinder, wrapped in bubble film for preservation, and transported back to the laboratory on the same day. The basic physical properties of loess samples were determined according to ASTM 2006 Standard Test Methods [22]. Particle size analysis was done using the Bettersize 2000 laser particle size tester. The results are shown in Table 1 and Figure 2.

2.2. Sample Preparation. An appropriate amount of undisturbed loess is fully crushed and is then placed in a constant temperature box at $108^{\circ} \mathrm{C}$ to dry. The dried loess is then sifted in a $2 \mathrm{~mm}$ sieve, and thereafter the soil sample is sprayed with a predetermined volume of water and stirred evenly until it reaches a moisture content of $10 \%$. The resultant sample is then sealed and stored in a plastic bag for 48 hours to balance the moisture of the soil sample. Next, the soil sample corresponding to the desired mass of the target dry density $\left(1.35 \mathrm{~g} / \mathrm{cm}^{3}, 1.40 \mathrm{~g} / \mathrm{cm}^{3}, 1.45 \mathrm{~g} / \mathrm{cm}^{3}, 1.50 \mathrm{~g} / \mathrm{cm}^{3}\right.$, $1.55 \mathrm{~g} / \mathrm{cm}^{3}$, and $1.60 \mathrm{~g} / \mathrm{cm}^{3}$ ) was weighed and put into a mold with a diameter of $61.8 \mathrm{~mm}$ and a height of $20 \mathrm{~mm}$. Then, the soil sample was subjected to static pressure at a constant rate. After compaction, the sample was taken out of the mold. Twelve samples were made in this way for each design dry density, which was divided into 2 groups of parallel samples. Finally, to get the compacted soil samples of different water contents, the water film transfer method was used to make 5 samples in each group of soil dry density samples each with a water content of $13 \%, 16 \%, 19 \%$, and $22 \%$, respectively, resulting in 30 different combinations of dry density and water content for the compacted soil samples. The water film transfer method requires the slow and even addition of water droplets to the surface of the sample. When the moisture content of the sample reaches the required level, the sample is placed in a sealed moisturizing tank for $48 \mathrm{~h}$ and then taken out for testing.

2.3. Electrical Resistivity Test. Studies show that AC power can effectively reduce the soil resistivity test error, and the soil resistivity is relatively stable when the test frequency is within the range of $50-500 \mathrm{~Hz}$, which can be used to characterize the soil particle characteristics, pore characteristics, and pore hydration rating characteristics [23]. Therefore, considering the stability and convenience of sample resistance testing, $1 \mathrm{~V}$ and $100 \mathrm{~Hz}$ alternating current were used for indoor resistivity testing in this study. This research uses the type TH2810D LCR digital bridge to test the resistance value of each sample. The instrument's current frequency ranges between 100 and $10 \mathrm{kHz}$, the test signal source voltage ranges between 0.1 and $1.0 \mathrm{~V}$, the impedance 


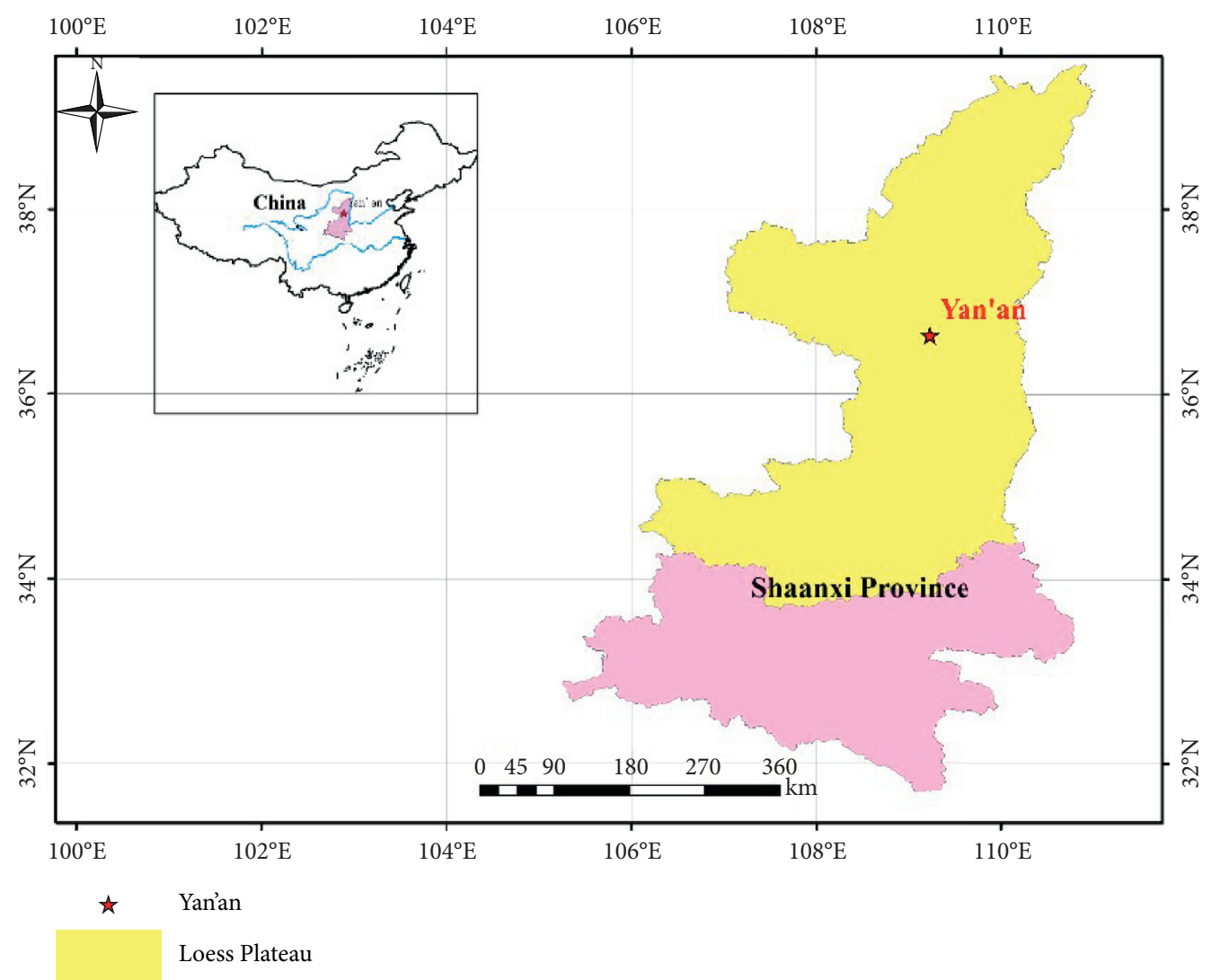

Figure 1: Loess distribution and sampling sites in Shaanxi, China.

TABle 1: Physical and mechanical parameters of the studied loess.

\begin{tabular}{|c|c|c|c|c|c|c|c|}
\hline \multirow{2}{*}{ Density $\left(\mathrm{g} / \mathrm{cm}^{3}\right)$} & \multirow{2}{*}{ Water content (\%) } & \multirow{2}{*}{ Specific gravity } & \multirow{2}{*}{ Liquid limit (\%) } & \multirow{2}{*}{ Plastic limit (\%) } & \multicolumn{3}{|c|}{ Grain size fractions (\%) } \\
\hline & & & & & $<0.005 \mathrm{~mm}$ & $0.005-0.075 \mathrm{~mm}$ & $>0.075 \mathrm{~mm}$ \\
\hline 1.38 & 11 & 2.72 & 27 & 18 & 9.96 & 82.22 & 7.82 \\
\hline
\end{tabular}

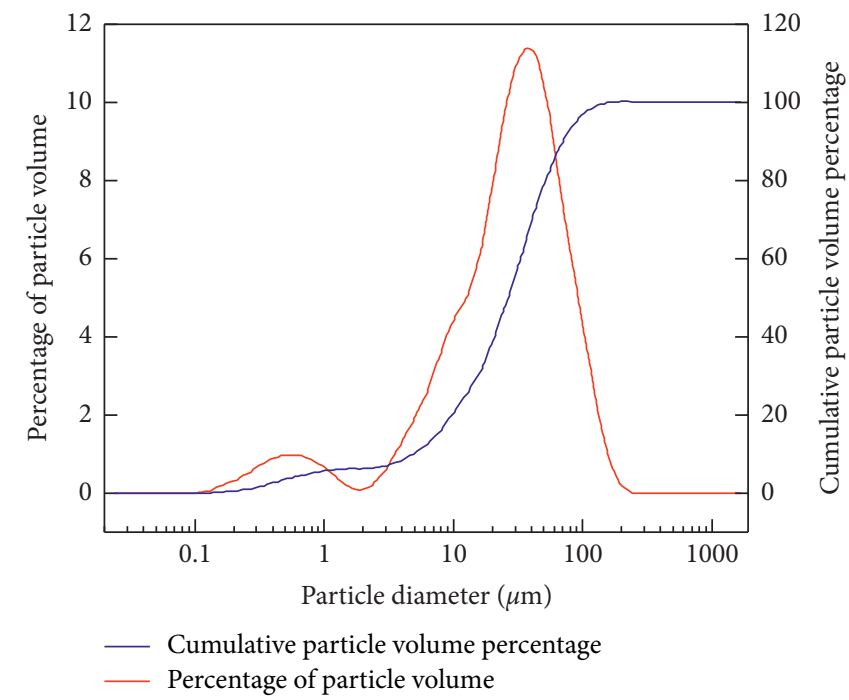

Figure 2: Loess sample size composition. 
measurement ranges between 0 and $100 \mathrm{M} \Omega$, and the accuracy is $0.1 \%$, which meets the test requirements.

During the test, a copper electrode plate with a diameter of $50 \mathrm{~mm}$ was placed on each of the upper and lower end faces of the sample, and a wire connecting the copper electrode plate was used to connect the test fixture to ensure that the copper electrode plate was in close contact with the surface of the sample. Thereafter, the stable data were read. Each sample was tested continuously for 10 times, and the average value was taken as its final resistivity value, to ensure the reliability of the results. Additionally, the test process is always controlled at room temperature of $25^{\circ} \mathrm{C}$, and the test time is short, so there is no need to modify the temperature of the resistance test results. The resistance of each sample was measured in turn using this method, and then the resistivity of the sample was calculated using the following formula:

$$
\rho=\frac{R S}{L}
$$

where $\rho$ is the resistivity $(\Omega \cdot \mathrm{m})$ in the type, $R$ is the resistance $(\Omega), S$ is the cross-sectional area of soil sample $\left(\mathrm{m}^{2}\right)$, and $L$ is the electrode spacing $(\mathrm{m})$.

2.4. Collapsibility Test. This study is based on the two-line method [24] to determine the collapsibility coefficient of compacted loess. The compression test is carried out with the triple high-pressure consolidation apparatus. The test pressures of all soil samples are loaded step by step according to $50,100,150$, and $200 \mathrm{kPa}$. In each group of 2 samples, one of the samples maintains the natural moisture content during the process of increasing the test stepped pressure and the other sample is deformed and stabilized under a pressure of $50 \mathrm{kPa}$. The stability standard is that the sample is deformed twice per hour. The amount is not more than $0.01 \mathrm{~mm}$. Thereafter, water is added from the top surface of the sample, and after it stabilizes again, the sample is further pressurized for the test. After the sample is stabilized under each pressure load, the height of the sample is recorded.

The collapsibility coefficient of the quantitative evaluation index of loess collapsibility is obtained by usingthe following formula :

$$
\delta_{s}=\frac{h_{1}-h_{2}}{h_{0}} .
$$

In the formula, $h_{1}$ is the height of the sample after deformation and stability under a certain level of pressure $(\mathrm{mm}) ; h_{2}$ is the height of the sample after collapsing and stable deformation under a certain level of pressure $(\mathrm{mm})$; and $h_{0}$ is the initial height of the sample ( $\left.\mathrm{mm}\right)$.

According to the Chinese National Standard (CNS) GB50025-2018 [25], in actual engineering construction, the collapsibility coefficient $\delta_{s}$ of loess under $200 \mathrm{kPa}$ pressure is mainly used as the standard to quantitatively evaluate its collapsibility: when $\delta_{s} \leq 0.015$, loess has no collapsibility; when $0.015 \leq \delta_{s} \leq 0.030$, the collapsibility is slight; when $0.03 \leq \delta_{s} \leq 0.070$, the collapsibility is medium; and when $\delta_{s}>0.070$, it is highly collapsible.

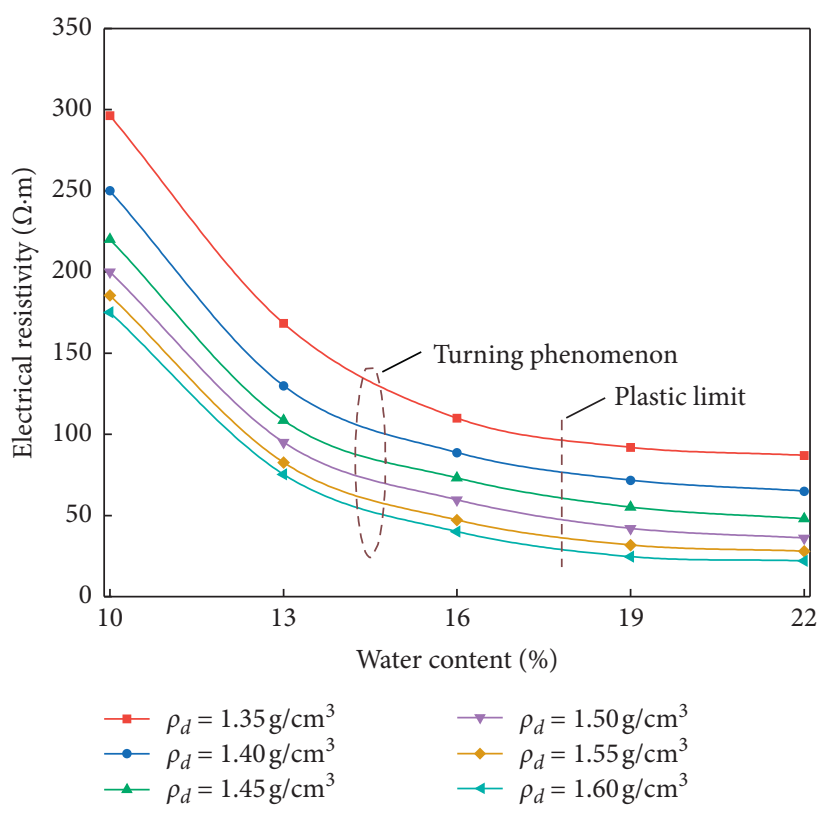

FIgURE 3: Relation between resistivity and water content of compacted loess.

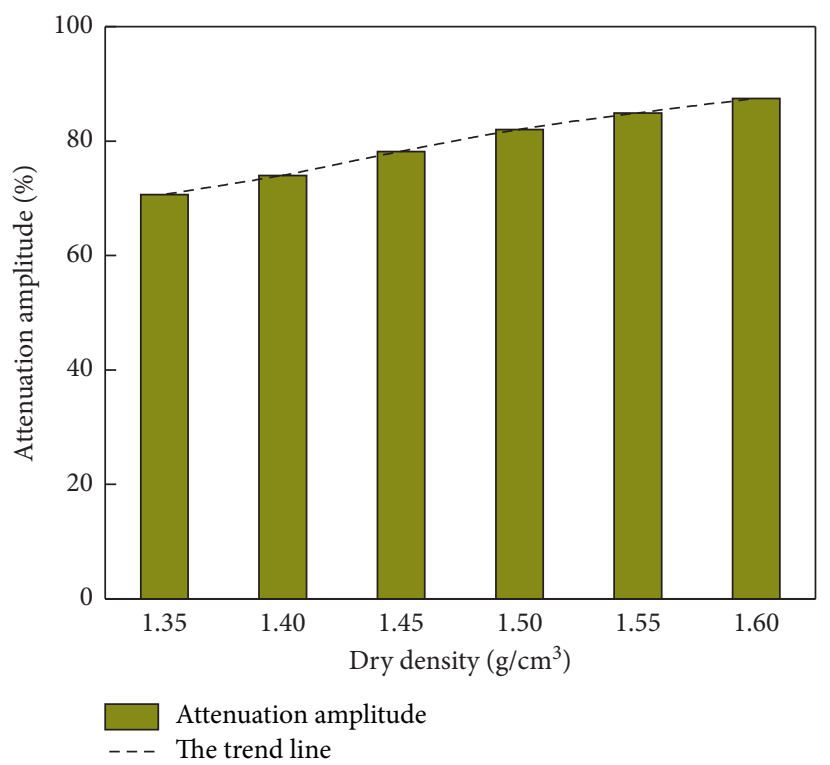

Figure 4: Attenuation amplitude of resistivity with dry density.

\section{Results and Discussion}

3.1. Electrical Resistivity of Compaction Loess. According to the resistance measurement result of the loess sample, the resistivity value of each loess sample is obtained by formula (1), and the change of soil sample resistivity with water content is reflected in Figure 3. Figure 4 shows the resistivity attenuation amplitude of the sample under different dry densities when the sample undergoes the same step-wise increase in water content (i.e., 12\%).

From Figure 3, we see that the resistivity of the compacted loess sample decreases significantly with an increase 
in water content. When the water content is $10 \%$, the resistivity range of the sample is $175-296.4 \Omega \cdot \mathrm{m}$; when the water content is $13 \%$, the resistivity range of the sample is $75.2-168.4 \Omega \cdot \mathrm{m}$; when the water content is $16 \%$, the resistivity range of the sample is $40-110 \Omega \cdot \mathrm{m}$; when the water content is $19 \%$, the resistivity range of the sample is $24.6-92 \Omega \cdot \mathrm{m}$, and when the water content is $22 \%$, the resistivity range of the sample is $22-87 \Omega \cdot \mathrm{m}$. In the whole process of increasing the water content from $10 \%$ to $22 \%$, the resistivity attenuation amplitude $(\Delta \rho / \rho)$ of the sample is as high as $70.64-87.42 \%$.

Figure 4 shows the resistivity attenuation amplitude of the sample under different dry densities when the sample undergoes the same increase in water content (i.e., 12\%). It can be found that the attenuation amplitude of resistivity of samples with a dry density of $1.60 \mathrm{~g} / \mathrm{cm}^{3}$ is $16.77 \%, 13.42 \%$, $9.24 \%, 5.42 \%$, and $2.51 \%$ higher than that of samples with a dry density of $1.35 \mathrm{~g} / \mathrm{cm}^{3}, 1.40 \mathrm{~g} / \mathrm{cm}^{3}, 1.45 \mathrm{~g} / \mathrm{cm}^{3}, 1.50 \mathrm{~g} / \mathrm{cm}^{3}$, and $1.55 \mathrm{~g} / \mathrm{cm}^{3}$, respectively, indicating that the increase in dry density can aggravate the attenuation of sample resistivity with water content.

In the water content-resistivity relationship curve of the compacted loess sample, we can not only observe the significant decrease in the electrical resistivity caused by the increase in water content but also find that the curve has a turning phenomenon, namely, for the water content there is a critical value (about 14\%), when the sample water content is less than the critical value of the moisture content-resistivity curve slope (i.e., the resistivity increases with the water content increase and the speed of attenuation). This means that lower incremental water content increases can cause large attenuation of resistivity, but when the water content increased gradually to the critical value, the attenuation rate of the resistivity is markedly decreased. Moreover, with the subsequent increase in the water content, the attenuation amplitude of resistivity becomes smaller and smaller. When the moisture content increases to about $18 \%$ (the plastic limit of soil samples used in this study), the attenuation amplitude of resistivity tends to a stable state.

The above phenomenon of the change in the resistivity of compacted loess with water content can be explained in Figure 5. For soil, the moisture in the pores is the main conductive medium. When the dry density of the soil is constant and the water content is small, due to the presence of air in the pores, the pore water in the soil is divided by it, and a good path cannot be formed. The conductivity of the soil is poor, so the resistivity is high. As the water content increases, more water will fill the pores of the soil, and the pore water content will increase, and the connectivity of the pore water will be significantly improved. This will directly cause the soil to have a larger conductive area and shorten the path so that the sample transfers current [26]. In addition, the increase in water content of the sample can also increase the thickness of the electric double layer on the surface of the soil particles to a certain extent [27], thereby increasing the conductivity of the surface of the soil particles. The electrical conductivity is also effectively improved, which causes the electrical resistivity of the soil to decrease drastically with the increase in water content. When the water content increases to a certain level, the connectivity of the pore water in the soil has reached a better state, and then the continued increase in water content has little effect on the connectivity of pore water. The resistivity of the soil then only decreases to a small extent or no longer changes with a continuous increase in water content because the water content has reached its limit of influence on the resistivity. The influence of water content on resistivity can be called the "water connectivity effect" of resistivity changes. The interactive effect of dry density can be explained as follows: the higher the dry density, the smaller the pores of the sample, and the greater the connectivity of the pore water, which leads to an increase in the attenuation of sample resistivity.

Figure 6 shows the variation of the resistivity of the compacted loess sample with the dry density. From the figure, we see that the resistivity of the sample decreases with an increase in the dry density, which is basically due to the influence of water content on resistivity. When the dry density of the sample is $1.35 \mathrm{~g} / \mathrm{cm}^{3}$, the resistivity range of the sample is $87-296.4 \Omega \cdot \mathrm{m}$; when the dry density is $1.4 \mathrm{~g} / \mathrm{cm}^{3}$, the resistivity range of the sample is $65-250 \Omega \cdot \mathrm{m}$; when the dry density is $1.45 \mathrm{~g} / \mathrm{cm}^{3}$, the resistivity range of the sample is $48-220 \Omega \cdot \mathrm{m}$; when the dry density is $1.5 \mathrm{~g} / \mathrm{cm}^{3}$, the resistivity range of the sample is $36-200 \Omega \cdot \mathrm{m}$; when the dry density is $1.55 \mathrm{~g} / \mathrm{cm}^{3}$, the resistivity range of the sample is $28-185.6 \Omega \cdot \mathrm{m}$; and when the dry density is $1.6 \mathrm{~g} / \mathrm{cm}^{3}$, the resistivity range of the sample is $22-175 \Omega \cdot \mathrm{m}$. During the increase in the dry density from $1.35 \mathrm{~g} / \mathrm{cm}^{3}$ to $1.6 \mathrm{~g} / \mathrm{cm}^{3}$, the resistivity attenuation range $(\Delta \rho / \rho)$ of the sample ranged from 40.96 to $74.71 \%$.

In addition, as shown in Figure 7, in the same dry density increase (i.e., $0.25 \mathrm{~g} / \mathrm{cm}^{3}$ ), the attenuation amplitude of the resistivity of samples with a water content of $22 \%$ is $33.75 \%$, $19.37 \%, 11.07 \%$, and $1.45 \%$ higher than that of samples with a water content of $10 \%, 13 \%, 16 \%$, and $19 \%$, respectively. These data show that the increase in water content has an aggravating effect on the attenuation of the sample resistivity with dry density.

Figure 8 explains the mechanism that influences the abovementioned compacted loess dry density on resistivity. When the moisture content stays constant and the dry density is small, the contact degree between soil particles is poor, and the porosity is also relatively large. In addition, the pore water is divided into independent units by the air, with poor connectivity between each other, resulting in a few current paths. Therefore, the conductivity of the soil is poor, which results in a high resistivity [28]. As the dry density increases (i.e., the degree of compaction increases), the total pore volume in the soil sample decreases, the soil particles are in closer contact, and the current is conducted better. Meanwhile, the saturation of the soil sample has been improved to a certain extent, and the communication paths of pore water in the soil increase, thereby increasing the conductive area and shortening the conductive path, which reduces the resistance of current conduction in the sample and leads to the gradual decrease in resistivity. The influence that dry density has on resistivity can be called the "compaction effect" of resistivity changes. At the same time, because the increase in pore water can 


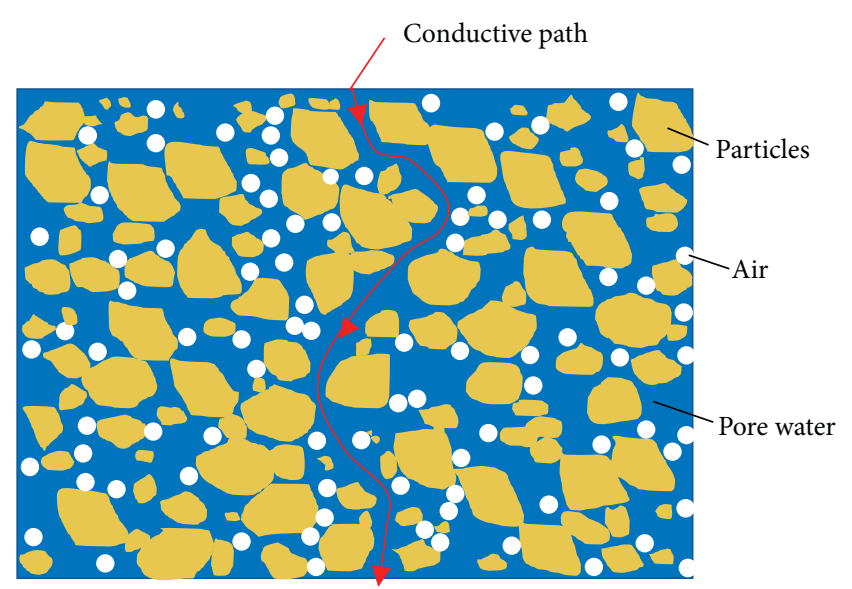

(a)

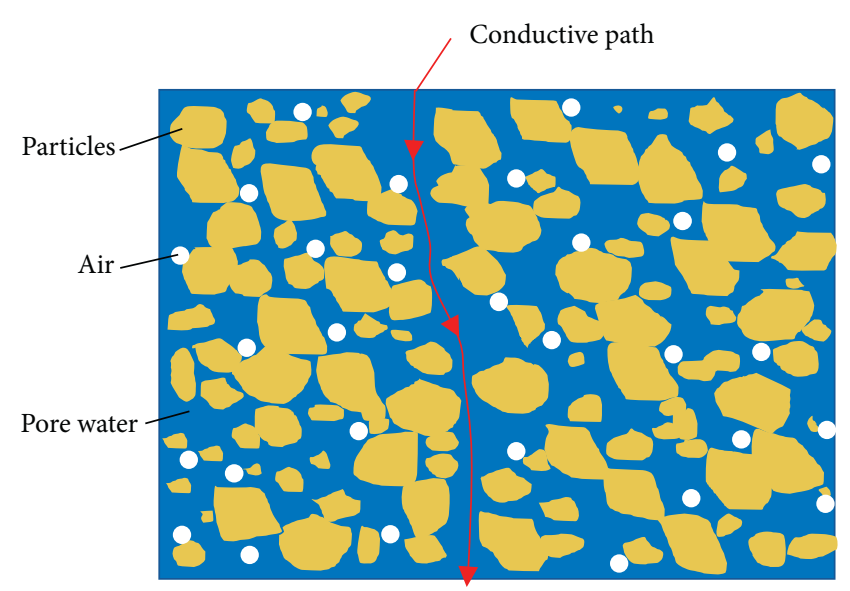

(b)

FIGURE 5: Schematic diagram of the conductive path changes of the compacted loess with different water content: (a) where water content is low and (b) where water content is high.

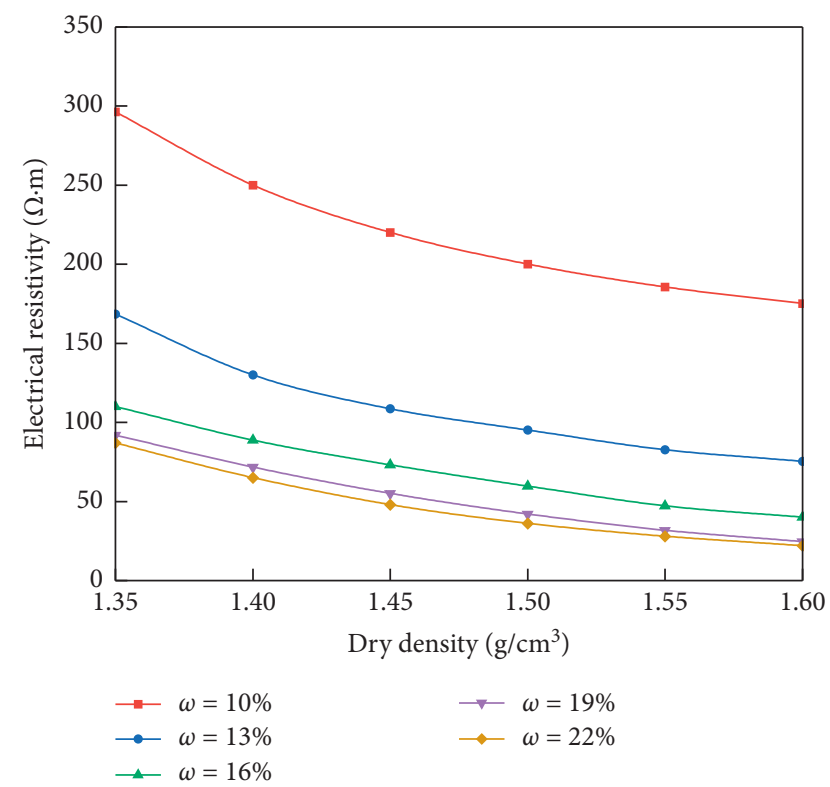

FIgURE 6: Relation between resistivity and dry density of compacted loess.

significantly reduce the resistivity of the sample, the water content has the effect of intensifying the attenuation of the resistivity of the sample with the dry density. In addition, when comparing Figures 4 and 7, it can be seen that the dry density has a smaller effect on the resistivity of the sample, which can be interpreted as the decrease in pore volume caused by the increase in dry density. This not only increases the saturation of the sample but also reduces the connectivity of pores, resulting in a small attenuation rate for the resistivity.

Based on the above analysis, the dynamic change of the resistivity of compacted loess can be attributed to the interactive influence of both the dry density and water content on the conductive path and conductive area of the soil. In other words,

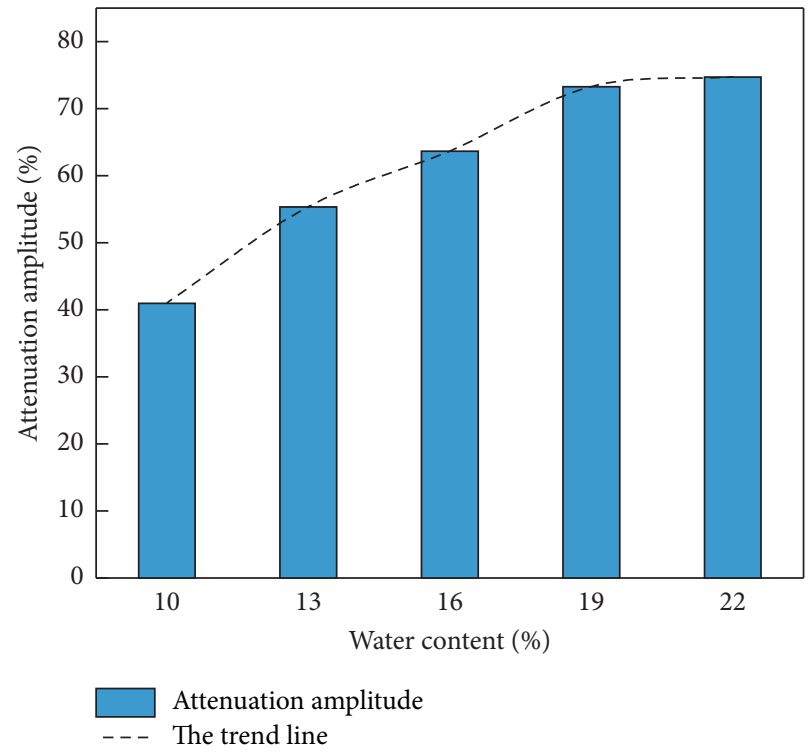

FIgURE 7: Attenuation amplitude of resistivity with water content.

it is a comprehensive superposition reflection of the "water connectivity effect" and "compaction effect" inside the soil.

3.2. Collapsibility Coefficient of Compaction Loess. Figure 9 shows the relationship between the collapsibility coefficient, the water content, and the dry density of loess under $200 \mathrm{kPa}$ pressure. This was obtained from a collapsibility test. At a constant dry density, the collapsibility coefficient of the sample gradually decreases with an increase in water content, and under constant water content, the collapsibility coefficient of the sample gradually decreases with an increase in dry density. When comparing Figures 3, 6 , and 9, we find that the influence trends of dry density and moisture content on the collapsibility coefficient and resistivity are similar. 


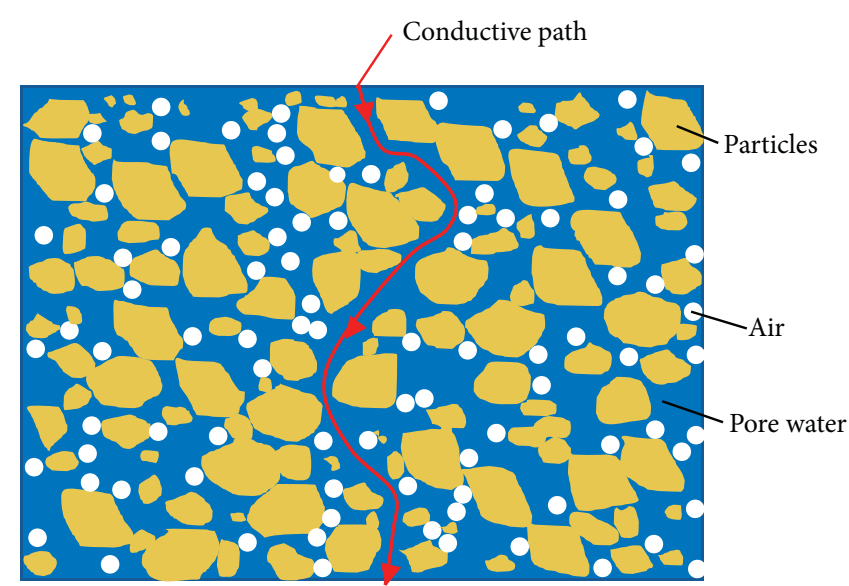

(a)

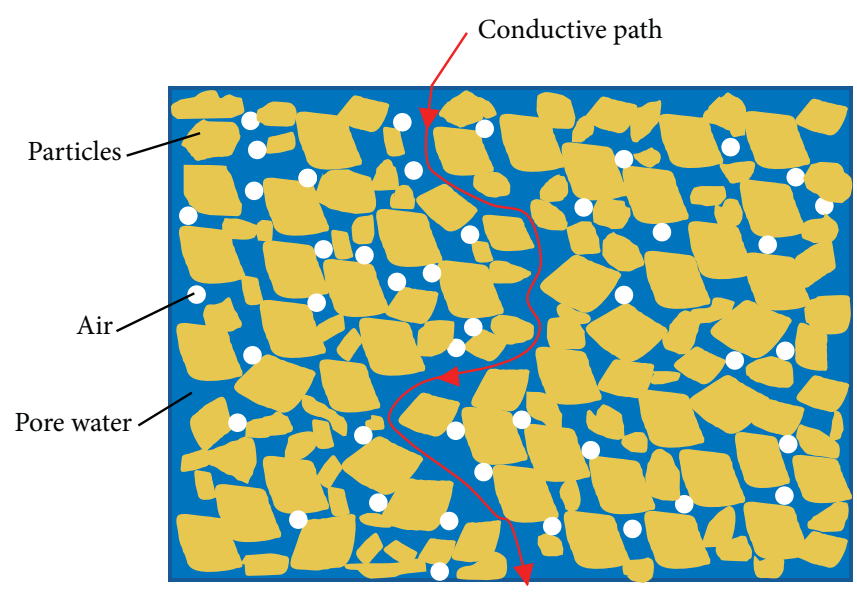

(b)

Figure 8: Schematic diagram of the conductive path changes of compacted loess with different dry densities: (a) a low dry density and (b) a high dry density.

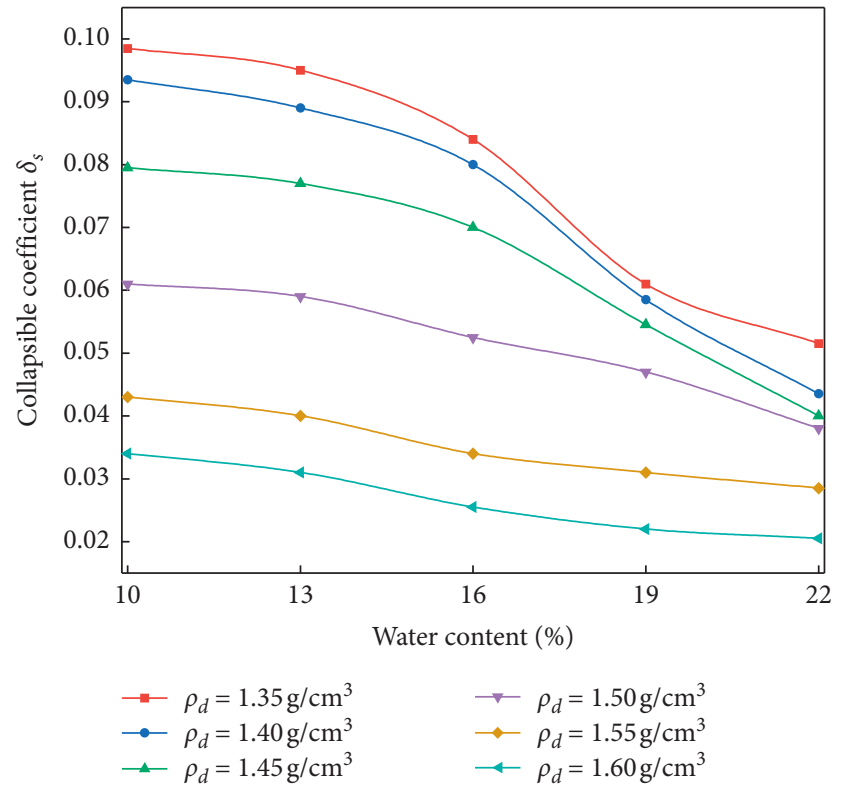

(a)

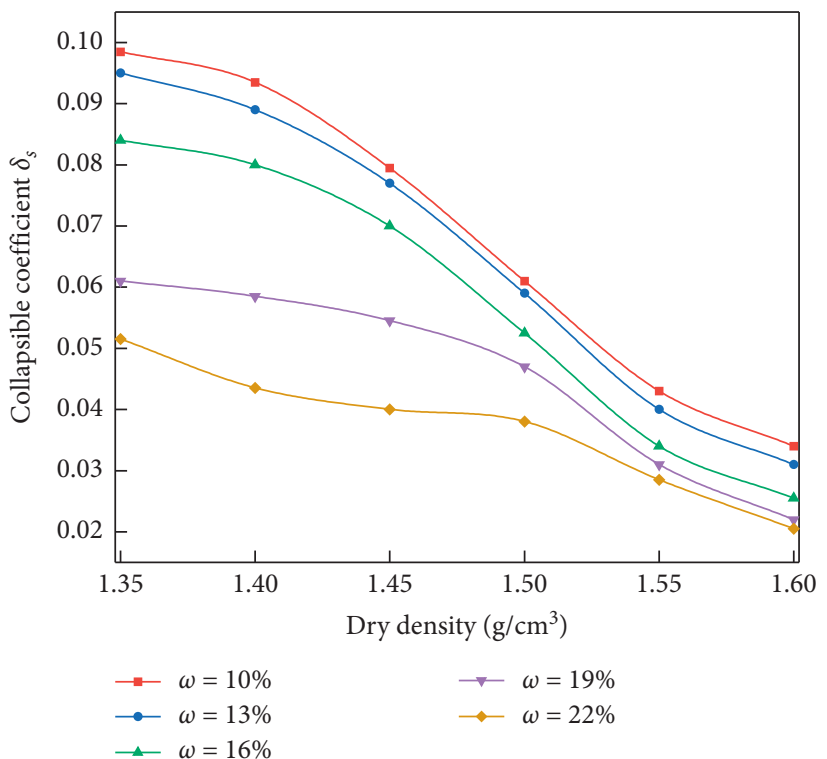

(b)

FIGURE 9: Variation of the collapsibility coefficient under different dry densities and water contents: (a) with a variation in water content and (b) with a variation in dry density.

3.3. Correlation between the Loess Collapsibility Coefficient and Resistivity. The change in resistivity of compacted loess with water content and dry density can be attributed to the "water connectivity effect" and "compaction effect," which is essentially a reflection of the soil microstructure characteristics. At the same time, soil microstructure is precisely the main factor that affects loess collapsibility $[29,30]$, and collapsibility is the external macroscopic manifestation of loess microstructure changes [31]. Therefore, in theory, it is feasible to use the resistivity of loess to describe the size and variation of the collapsibility coefficient.

The data in Figures 3, 6, 9, and 10 show the statistical relationship between the resistivity of compacted loess under different dry densities and different water contents and the collapsibility coefficient under $200 \mathrm{kPa}$ pressure. It can be seen from these figures, regardless of whether it is under constant dry density or constant water content, the resistivity of compacted loess and the collapsibility coefficient show a strong positive correlation. In other words, the resistivity of compacted loess and the collapsibility coefficient have a certain degree of quantitative correlation.

To be able to use the resistivity of compacted loess to quantitatively evaluate its collapsibility, it is crucial to establish the relationship between the sample's collapsibility coefficient, its resistivity, and simple physical indicators (such as dry density and water content) that can be directly measured in the room. It 


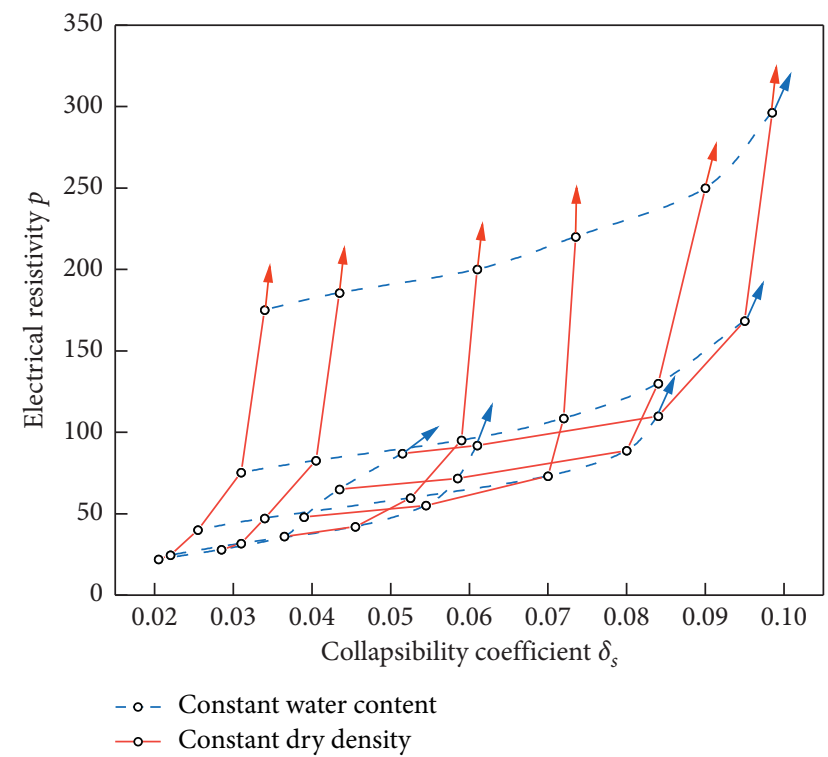

FIGURE 10: The relationship between the collapsibility coefficient and the resistivity.

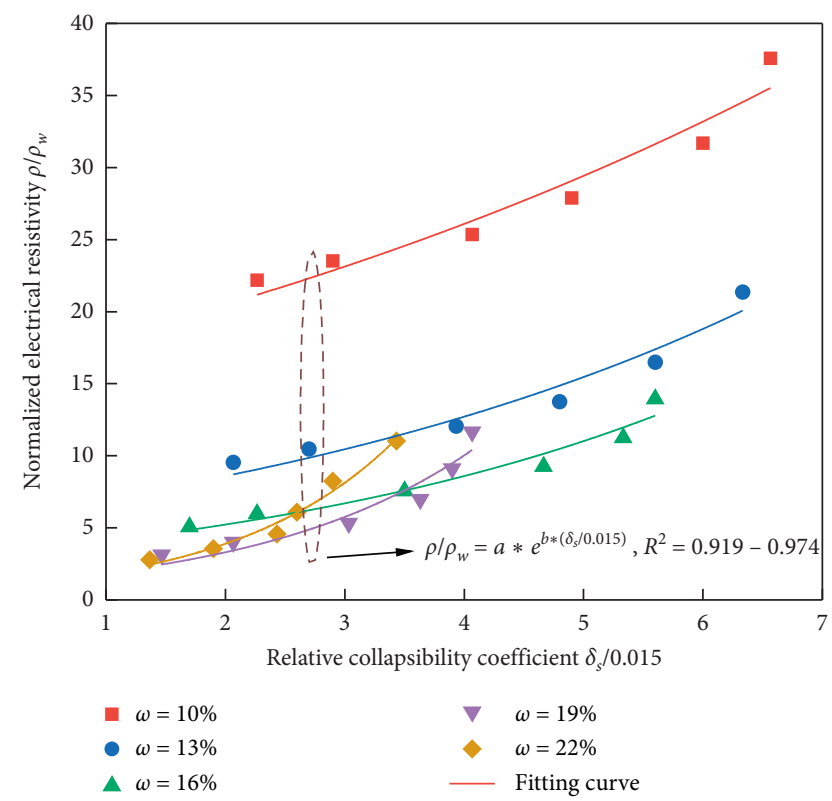

FIGURE 11: The relation curve between normalized resistivity and relative collapsibility coefficient.

should also be noted that pore water conductivity is one of the factors that cause changes in soil conductivity [32]. To eliminate the influence of pore water conductivity, this study set the ratio of the overall resistivity of the soil to the resistivity of the pore water (this study measured the value of $7.89 \Omega \cdot \mathrm{m}$ ) as the normalized resistivity. Since the collapsibility coefficient of loess is less than 0.015 , it can be considered as no longer collapsible, so the ratio of the collapsibility coefficient to 0.015 is defined as the relative collapsibility coefficient to establish a prediction model of the loess collapsibility coefficient based on the normalized resistivity.
Figure 11 shows the variation of the normalized resistivity of compacted loess with the relative collapsibility coefficient under different water contents and dry density states. When the moisture content is constant, the normalized resistivity of loess samples with different dry densities decreases along the same curve, that is to say, under the condition of the same water content, the relationship between normalized resistivity and relative collapsibility coefficient has nothing to do with dry density. Under the same water content state, the relationship between the normalized resistivity and the relative collapsibility coefficient is obtained by fitting the following equation:

$$
\frac{\rho}{\rho_{w}}=a \times e^{b \times\left(\delta_{s} / 0.015\right)} .
$$

In the formula, $\rho$ is the resistivity of compacted loess, $\rho_{w}$ is the resistivity of pore water, and $a$ and $b$ are fitting parameters. The specific relational expressions under different water contents are listed in Table 2.

It can be seen from Table 2 that the range of the fitting parameter $a$ in the formula is $0.895-16.119$, which decreases with an increase in water content, and the range of the fitting parameter $b$ is $0.120-0.735$, which increases with an increase in water content. To further refine the correlation between the normalized resistivity of the compacted loess and the relative collapsibility coefficient, the relationship between the parameters $a$ and $b$ and the water content is fitted, and the variation of the fitting parameters $a$ and $b$ with the water content is obtained, as shown in Figure 12.

It can be seen from the figure that the fitting parameter $a$ decreases exponentially with the water content, and the specific expression is

$$
a=92613.30 \times w^{-3.76} .
$$

The fitting parameter $b$ and the water content increase linearly, and the specific expression is

$$
b=0.053 \times w-0.477 \text {. }
$$

Substituting formulas (4) and (5) into formula (3), the normalized resistivity and relative collapsibility coefficient of compacted loess can be expressed as

$$
\frac{\rho}{\rho_{w}}=92613.30 \times w^{-3.76} \times e^{(0.053 \times w-0.477) \times\left(\delta_{s} / 0.015\right)} .
$$

By further transforming formula (6), the expression of the resistivity and the collapsibility coefficients of compacted loess can be obtained as

$$
\delta_{s}=\frac{0.015}{0.053 \times w-0.477} \ln \frac{\rho}{92613.30 \times w^{-3.76} \rho_{w}} .
$$

Equation (7) is the prediction model of the collapsibility coefficient area based on the resistivity index.

Based on the above research and the analysis results, the regional prediction formula can be extended to the generalized prediction model:

$$
\delta_{s}=\frac{0.015}{b} \ln \frac{\rho}{a \rho_{w}} .
$$


TABLE 2: The relationship between the normalized resistivity and the relative collapsibility coefficient under different water contents.

\begin{tabular}{lcc}
\hline Water content $(\%)$ & Normalized resistivity & Correlation coefficient $R^{2}$ \\
\hline 10 & $\rho / \rho_{w}=16.119 \times e^{0.120 \times\left(\delta_{s} / 0.015\right)}$ & 0.939 \\
13 & $\rho / \rho_{w}=5.813 \times e^{0.196 \times\left(\delta_{s} / 0.015\right)}$ & 0.948 \\
16 & $\rho / \rho_{w}=3.180 \times e^{0.248 \times\left(\delta_{s} / 0.015\right)}$ & 0.949 \\
19 & $\rho / \rho_{w}=1.09 \times e^{0.555 \times\left(\delta_{s} / 0.015\right)}$ & 0.919 \\
22 & $\rho / \rho_{w}=0.895 \times e^{0.735 \times\left(\delta_{s} / 0.015\right)}$ & 0.974 \\
\hline
\end{tabular}

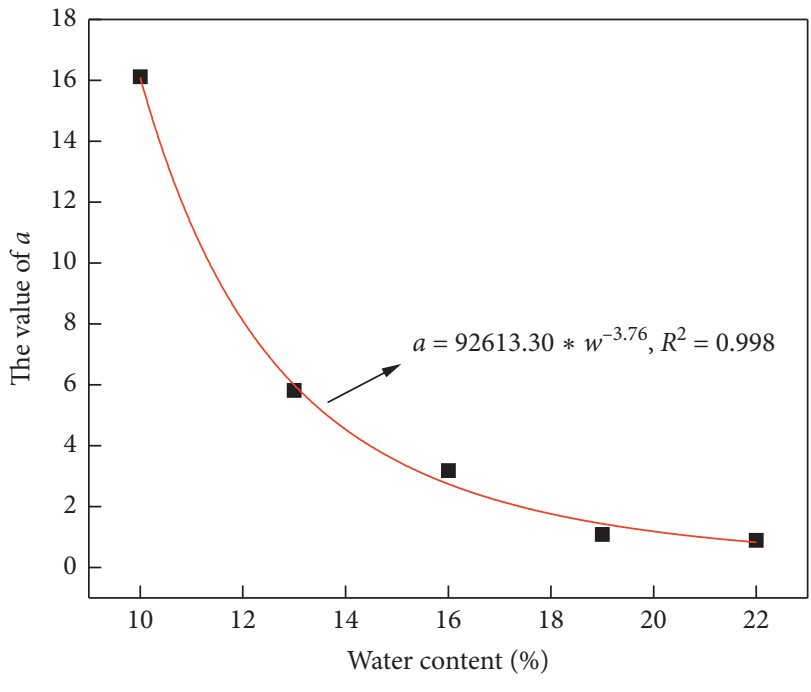

- The value of $a$ — Fitting line

(a)

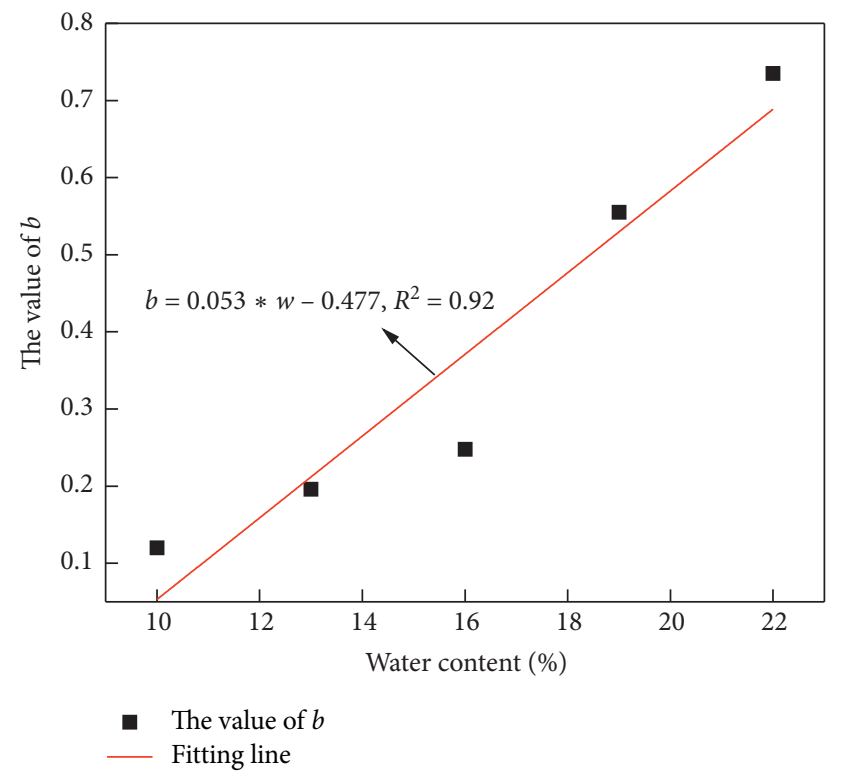

(b)

Figure 12: The relationship curve between the fitting parameters and the water content. (a) The value of $a$. (b) The value of $b$.

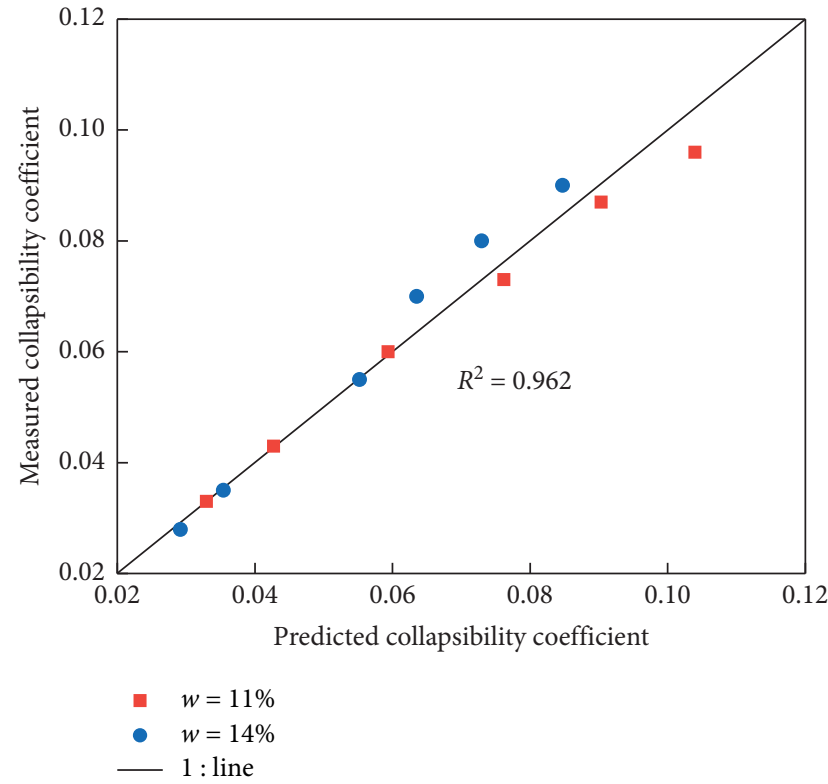

Figure 13: Comparison of test results and predicted results.

In the formula, $\rho$ is the resistivity of the compacted loess, $\rho_{w}$ is the resistivity of the pore water, and both a and $b$ are soil parameters related only to water content.
To verify the applicability and accuracy of the collapsibility coefficient prediction model based on the resistivity index, the same loess was selected in this study and the water content was $11 \%$ and $14 \%$ according to the same method, and the corresponding dry density was $1.35 \mathrm{~g} / \mathrm{cm}^{3}, \quad 1.40 \mathrm{~g} / \mathrm{cm}^{3}, \quad 1.45 \mathrm{~g} / \mathrm{cm}^{3}, 1.50 \mathrm{~g} / \mathrm{cm}^{3}$, and $1.55 \mathrm{~g} / \mathrm{cm}^{3}$ and $1.60 \mathrm{~g} / \mathrm{cm}^{3}$ for 12 compacted loess samples, and using the collapsibility coefficient of these 12 samples verification. Figure 13 shows the correlation between the measured value of the collapsibility coefficient of these samples and the predicted value obtained from equation (7). It can be found that the correlation coefficient between them reaches 0.962 , which fully proves the rationality and feasibility of using the collapsibility coefficient based on the resistivity index of the compressed loess presented in this study, as a prediction model, and it can be used to predict the collapsibility of compacted loess in the Loess Plateau, especially in Yan'an area.

In summary, for compacted loess, only the water content, electrical resistivity, and pore water electrical resistivity of the samples are measured, and then the prediction model proposed in this study can be used to calculate and evaluate its collapsibility without measuring other physical and mechanical indexes. Therefore, as an economical and time- 
saving nondestructive testing method, using resistivity to study and evaluate the collapsibility of compacted loess has significant advantages.

\section{Conclusion}

In this research, we analyzed the correlation between collapsibility coefficient and resistivity using the indoor collapsibility test and resistivity test of compacted loess with different water contents and dry densities. We propose a new model for predicting the loess collapsibility coefficient by using the resistivity method. Through the systematic analysis of the test results, the following conclusions can be drawn.

(1) The resistivity of the compacted loess is significantly negatively correlated with the dry density and water content, and there is a critical water content at which the decay rate of resistivity with increasing water content present two different states: when the water content is lower than the critical value, the resistivity decay rate is relatively fast, and when the water content exceeds the critical value, the resistivity decay rate is significantly reduced. Thereafter, when the water content continues to increase to near the plastic limit, the resistivity decay rate is flat.

(2) The influence of water content and dry density on the resistivity of compacted loess can be attributed to the combination of the "water connection effect" and the "compaction effect," and the influence of the moisture content on the resistivity of compacted loess is more pronounced than the effect of dry density on resistivity.

(3) Under conditions of constant dry density or constant water content, the resistivity of compacted loess has a strong positive correlation with the collapsibility coefficient under $200 \mathrm{kPa}$ pressure, and the influence trends of dry density and water content on resistivity and collapsibility are qualitatively similar. Therefore, theoretically, resistivity can be used to evaluate the collapsibility of compacted loess, which is a relatively economical and reliable nondestructive testing method.

(4) Based on the normalized resistivity $\rho / \rho_{w}$ and the relative collapsibility coefficient $\delta_{s} / 0.015$ of the compacted loess, a prediction model for the collapsibility of compacted loess is established. Only the moisture content, electrical resistivity, and pore water resistivity of the sample are measured, the collapsibility coefficient of the loess sample can be calculated to evaluate its collapsibility, and the calculated result is highly correlated with the test result.

These test results are of great significance for a better understanding of the relationship between resistivity and the collapsibility of China's compacted loess. In addition, the research results of the relationship between the resistivity index and the collapsibility of compacted loess should also apply to natural loess, which lays the foundation for our future research on the relationship between the collapsibility of natural loess and its electrical indicators.

\section{Data Availability}

The data used to support the findings of this study are available from the corresponding author upon request.

\section{Conflicts of Interest}

The authors declare that there are no conflicts of interest regarding the publication of this paper.

\section{Acknowledgments}

The authors gratefully acknowledge the Second Tibetan Plateau Scientific Expedition and Research (STEP) Program (Grant no. 2019QZKK0905), Key Program of the National Natural Science Foundation of China (Grant no. 41931285), and the Key Research and Development Program of Shaanxi Province (Grant no. 2019ZDLSF05-07).

\section{References}

[1] J. Peng, S. Qi, W. Ann, and A. D. Tom, "Preface to the special issue on "loess engineering properties and loess geohazards"," Engineering Geology, vol. 236, no. 1-3, 2017.

[2] J. Peng, G. Wang, Q. Wang, and F. Zhang, "Shear wave velocity imaging of landslide debris deposited on an erodible bed and possible movement mechanism for a loess landslide in Jingyang, Xi'an, China," Landslides, vol. 14, no. 4, pp. 1503-1512, 2017.

[3] E. Derbyshire, Landslides in the Thick Loess Terrain of NorthWest China, D. Edward, A. D. Tom, and M. Xingmin, Eds., Wiley, Hoboken, NJ, USA, 2000.

[4] S. J. Feng, F. L. Du, Z. M. Shi, W. H. Shui, and K. Tan, "Field study on the reinforcement of collapsible loess using dynamic compaction," Engineering Geology, vol. 185, pp. 105-115, 2015.

[5] H. Luo, F. Wu, J. Chang, and J. Xu, "Microstructural constraints on geotechnical properties of Malan Loess: a case study from Zhaojiaan landslide in Shaanxi Province, China," Engineering Geology, vol. 236, pp. 60-69, 2017.

[6] W. K. Ni, K. Z. Yuan, X. F. Lü, and Z. H. Yuan, "Comparison and quantitative analysis of microstructure parameters between original loess and remoulded loess under different wetting-drying cycles," Scientific Reports, vol. 10, no. 1, p. 5547, 2020.

[7] P. Qin, Y Liu, Z Song et al., "An electrical resistivity method of characterizing hydromechanical and structural properties of compacted loess during constant rate of strain compression," Sensors, vol. 20, no. 17, 2020.

[8] L. Xu, F. Dai, X. Tu, L. G. Tham, Y. Zhou, and J. Iqbal, "Landslides in a loess platform, North-West China," Landslides, vol. 11, no. 6, pp. 993-1005, 2014.

[9] G. Li, F. Wang, W. Ma et al., "Variations in strength and deformation of compacted loess exposed to wetting-drying and freeze-thaw cycles," Cold Regions Science and Technology, vol. 151, pp. 159-167, 2018. 
[10] D. Peng, Q. Xu, F. Liu et al., "Distribution and failure modes of the landslides in Heitai Terrace, China," Engineering Geology, vol. 236, pp. 97-110, 2018.

[11] J. Peng, Z. Fan, D. Wu et al., "Heavy rainfall triggered loessmudstone landslide and subsequent debris flow in Tianshui, China," Engineering Geology, vol. 186, pp. 79-90, 2015.

[12] X. A. Li, L. Wang, B. Hong, L. C. Li, J. Liu, and H. N. Lei, "Erosion characteristics of loess tunnels on the Loess Plateau: a field investigation and experimental study," Earth Surface Processes and Landforms, vol. 45, no. 9, pp. 19451958, 2020.

[13] J. Mingjing, H. Hu, and F. Liu, "Summary of collapsible behaviour of artificially structured loess in oedometer and triaxial wetting tests," Canadian Geotechnical Journal, vol. 49, no. 10, pp. 1147-1157, 2012.

[14] P. An, A. Zhang, Y. Xing, B. Zhang, W. Ni, and W. Ren, "Experimental study on settling characteristics of thick selfweight collapsible loess in Xinjiang Ili region in China using field immersion test," Soils and Foundations, vol. 58, no. 6, pp. 1476-1491, 2018.

[15] Y. M. Reznik, "Influence of physical properties on deformation characteristics of collapsible soils," Engineering $\mathrm{Ge}$ ology, vol. 92, no. 11, pp. 27-37, 2007.

[16] K. E. Gaaver, "Geotechnical properties of Egyptian collapsible soils," Alexandria Engineering Journal, vol. 51, no. 3, pp. 205-210, 2012.

[17] Y. Zhang, Z. Hu, and Z. Xue, "A new method of assessing the collapse sensitivity of loess," Bulletin of Engineering Geology and the Environment, vol. 77, pp. 1287-1298, 2018.

[18] L. Wang, S. Shao, and F. She, "A new method for evaluating loess collapsibility and its application," Engineering Geology, vol. 264, Article ID 105376, 2019.

[19] N. Asad, F. E. Jalal, and A. Naseem, "Predicting sandy-clayey soil properties using electrical resistivity testing," Proceedings of the Institution of Civil Engineers - Geotechnical Engineering, vol. 173, no. 1, pp. 21-29, 2020.

[20] M. Long, S. Donohue, J. S. L'Heureux et al., "Relationship between electrical resistivity and basic geotechnical parameters for marine clays," Canadian Geotechnical Journal, vol. 49, no. 10, pp. 1158-1168, 2012.

[21] G. O. Kang, M. D. Tan, S. L. Jae, and Y. S. Kim, "Evaluation of erosion resistance capacity on compacted weathered granite soil using non-destructive tests," Bulletin of Engineering Geology and the Environment, vol. 79, no. 2, pp. 1-17, 2020.

[22] ASTM, Annual Book of ASTM Standards, ASTM International, West Conshohocken, PA, USA, 2006.

[23] Y. Chu, S. Liu, B. Bate, and L. Xu, "Evaluation on expansive performance of the expansive soil using electrical responses," Journal of Applied Geophysics, vol. 148, pp. 265-271, 2017.

[24] L. Wang, X. A. Li, L. C. Li et al., "Characterization of the collapsible mechanisms of Malan loess on the Chinese loess Plateau and their effects on eroded loess landforms," Human and Ecological Risk Assessment: An International Journal, vol. 26, no. 9, pp. 2541-2566, 2020.

[25] Standardization Administration of China (SAC), M.o.C., China National Standards GB50025-2018: Standard for Building Construction in Collapsible Loess Regions, China Building Industry Press, Beijing, China, 2018, in Chinese.

[26] M. S. Hossain and G. Kibria, "Investigation of geotechnical parameters affecting electrical resistivity of compacted clays," Journal of Geotechnical and Geoenvironmental Engineering, vol. 138, no. 12, pp. 1520-1529, 2012.

[27] D. G. Fredlund, A. Xing, and S. Huang, "Predicting the permeability function for unsaturated soils using the soil- water characteristic curve," International Journal of Rock Mechanics and Mining Science \& Geomechanics Abstracts, vol. 32, no. 4, p. 159A, 1994.

[28] A. A. Bery and N. E. H. Ismail, "Empirical correlation between electrical resistivity and engineering properties of soils," Soil Mechanics and Foundation Engineering, vol. 54, no. 6, pp. 425-429, 2018.

[29] Y. N. Wei, W. Fan, B. Yu, L. S. Deng, and T. Wei, "Characterization and evolution of three-dimensional microstructure of Malan loess," Catena, vol. 192, Article ID 104585, 2020.

[30] X. Shao, H. Zhang, and Y. Tan, "Collapse behavior and microstructural alteration of remolded loess under graded wetting tests," Engineering Geology, vol. 233, pp. 11-22, 2018.

[31] Z. Liu et al., "Collapsibility, composition, and microstructure of loess in China," Canadian Geotechnical Journal, vol. 53, pp. 673-686, 2015.

[32] J. A. Munoz-Castelblanco, L. D. Siuts, T. C. Sheahan, J. M. Pereira, P. Delage, and Y. J. Cui, "The influence of changes in water content on the electrical resistivity of a natural unsaturated loess," Geotechnical Testing Journal, vol. 35, no. 1, pp. 11-17, 2012. 